\title{
ergonomic aspects
}

cabins

of earth

moving

machines 


\section{cabins of \\ earth-moving- machines}

\section{ergonomic aspects}

A joint publication by:

Foundation for occupation health in the building trade BOUW (P.O.Box 8114, 1005 AC Amsterdam)

INO Netherlands Institute for Preventive Health Care TNO, Leiden 


\section{Ergonomics Steering Committee}

Prof. H.J.Th. Span

Professor Extraordinarius

Road Construction (TH Delft)

Chairman

E.H. Mulder

First Medical Officer of the Dutch Inspectorate district Utrecht

D.P. Rookmaaker

Chairman of the Dutch

Ergonomics Society

W. van Hof

Director - Physician BGBouw

E.A.P. Koningsveld

BGBouw

Research Manager

\section{Studygroup Earthmoving machines}

D.P. Rookmaaker

H.T.M. van Eeden

H. Koman

E.A.P. Koningsveld

M.J. Pool

A. Suvaal

C. Zijlstra

Editors:

C.K. Pasmooij

M.P. v.d. Grinten
Chairman of the Dutch

Ergonomics Society,

Chairman

Dutch Labour Inspectorate

Representative of Trade Union of Construction - CNV

BGBouw, Research Manager

Physician Regional Occupational Health Centre, Alkmaar

Mechanical adviser, Dutch Labour Inspectorate

ABOMA

Netherlands Institute for

Preventive Health Care-TNO

Netherlands Institute for

Preventive Health Care-TNO 


\section{Preface}

The "Stichting Bedrijfsgezondheidsdienst voor de Bouwnijverheid" (Foundation for occupational health care in the Building Trade), BGBouw, protects and promotes occupational health care for all employees in the building trade and associated industry. Individual services, in the form of occupational medical assistance, are provided by more than fourty affiliated regional industrial health services. In addition scientific research is conducted, aimed at practical circumstances, with the purpose of analysing working conditions in the building trade and, where necessary, to point the way to improvement.

With the latter task in mind, BGBouw has instituted among others an Ergonomics Steering Committee, which was given the responsibility of setting up ergonomic research projects, to monitor their progress and publish the results.

In imitation of the surveys into tower crane cabins respectively cabins of mobile cranes, it was decided to request the Netherlands Institute for Preventive Health Care-TNO (NIPG) to conduct a similar survey into the cabins of earthmoving machines. Toassist in this survey, a study group was constituted, the composition of which is shown on the adjacent page. The research consisted of an inventory of national and intemational directives and instructions in respect of the layout of cabins of this class of equipment, an ergonomic assessment of 38 units of existing equipment, and interviews with 32 operators, whereby particular attention was paid to health, safety and comfort aspects.

The results of this survey were presented in a report "Cabins of earthmoving machines - an ergonomic field study and constructive recommendations", which was published by NIPG (in Dutch).

The recommendations of this report are presented in this brochure. Descriptions are given of how ergonomically designed cabins of earthmoving equipment will probably appear in future. This, on the one hand is important in the design of new machines, while on the other hand some of these recommendations have their use when existing equipment is being adapted.

The data presented in this booklet generally go farther than the minimum conditions applicable in the Nether- 
lands, and which are laid down in standards and governmental publications. Consequently these data do not represent official requirements.

Among designers and manufacturers an increased interest in the ergonomic aspects of cabins has been noted in recent years. This report, provided active support by purchasers and users of the equipment is obtained, can help in channelling the intentions that are presented. Hence this report should be seen, not as a subject for discussion, but as a working document!

December 1982 BGBouw 


\section{Introduction}

Following the surveys into the cabins of tower cranes (completed end 1979) and mobile cranes (completed mid 1981), the Netherlands Institute for Preventive Health Care - TNO (NIPG), conducted a similar survey into the cabins of earthmoving machines. The purpose of this study was to determine the situation prevailing in 1982 regarding the cabins of earthmoving machinery on the one hand. On the other hand, recommendations were to be formulated, on the basis of which ergonomically justified cabins may be constructed. From this survey an extensive NIPG report has been prepared ${ }^{*}$. The conclusions and recommendations of this report have been summarized in this brochure. The common denominator "earthmovers" coversa large number of different machines, which, however, all have in common that they are designed to move soil. "To move" in this context should be understood to mean "to work", and not to transport over considerable distances. This brochure deals with earthmoving machines in general use in the Netherlands, for road and hydraulic engineering construction, civil and public engineering projects, site preparation and for moving soil and materials. The following machines will be discussed:

\section{Wheel-loader}

*Pasmooij C.K. and M.P. van der Grinten. Cabins of earthmoving machines - an ergonomic field study and constructive recommendations (in Dutch). Netherlands Institute for Preventive Health Care TNO, Leiden 1982

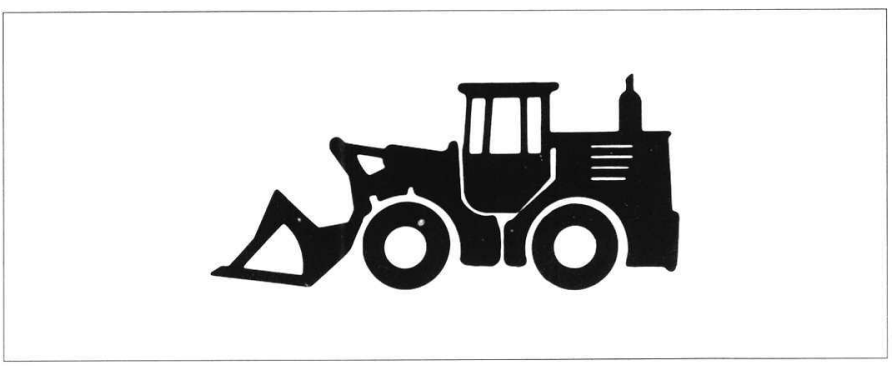

Its principal function is the loading of soil. In addition this machine is sometimes equipped with a special bucket for breaking up paving etc. Self-propelled transport between sites is possible. The wheel-loader generally loads while on the move, and is stationary when discharging. 


\section{Hydraulic excavator}
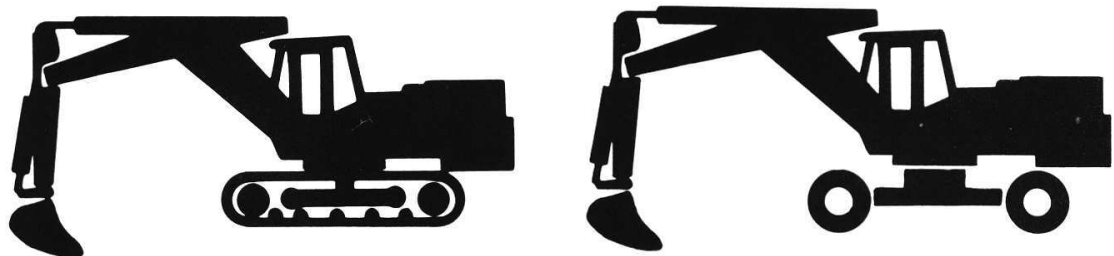

The most important function of the hydraulic excavator is digging. Different types of buckets can dig various trenches, holes, embankments etc. These machines may be mounted on a tracked chassis (the heavier types), or they may be wheeled (lighter types). Work is done with a stationary machine, either, or not, jacked up. Site preparation is carried out only by operating the moving equipment, the lifting and the digging arm, and by slewing the superstructure on the chassis turntable.

\section{Back-hoe loader}

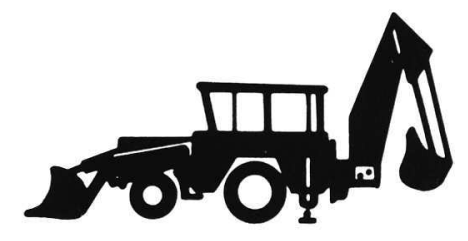

This is a combination of the machines described above. Digging and loading are both possible, but the moving equipment for the different functions is mounted at the front and the back of the machine. Hence the operator must turn around in the cabin, when he changes from one operation to the other. The chassis is often 
similar to that of the agricultural tractor and these machines are suitable mostly forsmall capacities. Digging is done with a stationary and jacked machine, while loading is performed with a moving machine.

\section{Bulldozer}

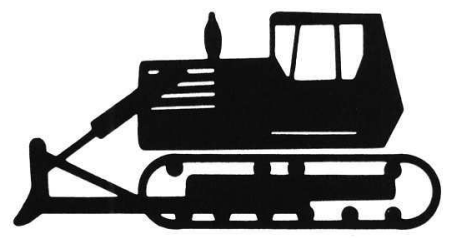

The principal function is displacing soil, with the objective of levelling of a site. The bulldozers, when equipped with a breaker jaw, are also used for breaking up paving etc. Bulldozers generally are heavily powered and they are almost always tracked. Their work is done while moving.

\section{Grader}

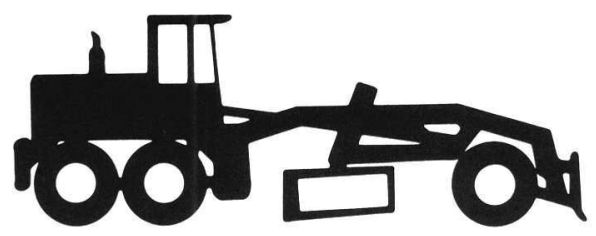

This type of macine is specially equipped for levelling, banking, spreading, pushing and making embankments. Adjustable blades are mounted on the machine at the lower centre and at the front. These machines can in 
many cases be moved by road under their own power. Work is done while the machine is moving.

\section{Dragline}

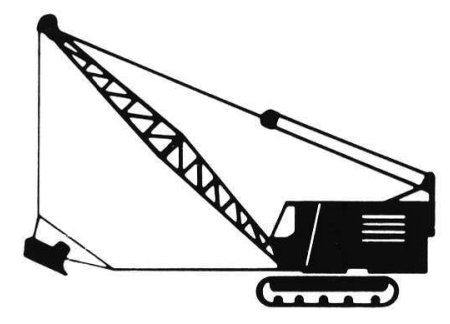

A dragline is employed when a site has to be excavated, embankments etc. have to be removed and/or levelled. The dragline as a rule has a tracked chassis. Work is done while the machine is stationary. 
This brochure is arranged as follows: Chapters 2-11 elaborate on recommendations which are made for ten different aspects of these cabins.

Chapter 2: $\quad$ Accessibility (Hand- and footrests, platforms, opening of door, emergency exits)

Chapter 3: $\quad$ Outward visibility (windowarea, reflections, windshield wipers, angles of visibility)

Chapter 4: $\quad$ Seating acommodation (seat dimensions, adjustability, material, vibration damping, position of seat in respect of controls)

Chapter 5: $\quad$ Cabin dimensions (freedom of movement, personal comfort)

Chapter 6: Operating controls (location, uniformity of operation, control forces, priorities)

Chapter 7: Presentation of data (instruments presenting data regarding machine condition and earthmoving process, legibility, location, completeness, priorities)

Chapter 8: $\quad$ Illumination (of cabin, site and moving equipment)

Chapter 9: $\quad$ Noise (with door open and closed, acoustic provisions)

Chapter 10: $\quad$ Vibration and shocks (vibration damping of tires, wheel suspension, chassis, cabin mountings and seats)

Chapter 11: Climate control and ventilation (temperature, humidity, sun shading, heating, insulation). 
In the case of recommendations that specifically refer to one or more types of machine, one or more symbols below the relevant text denote to which type of machine the relevant recommendation refers. In several places in the text reference is made to ISO Standards and their numbers. At the last page of this brochure these ISO Standards are listed, together with an explanatory text. For the description and explanation of these standards, reference is made to the earlier mentioned NIPG report. In the event that earthmoving machines are employed for hoisting or lifting activities, the safety requirements stated in the mobile cranes brochure* shall be applicable. The requirements laid down in the Dutch standards for cranes, such as NEN 2027 and NEN 2028, shall also then apply. 


\section{Accessibility}

Good accessibility must be assured, to prevent accidents while entering and leaving the machine and, that in case of emergency, the operator is able to leave the cabin quickly, without difficulty and without having to jump clear of the machine. The machine should also provide good access for maintenance activities. Only recommended access routes and provisions for the cabin are shown in the illustrations below (Fig. 2.1).

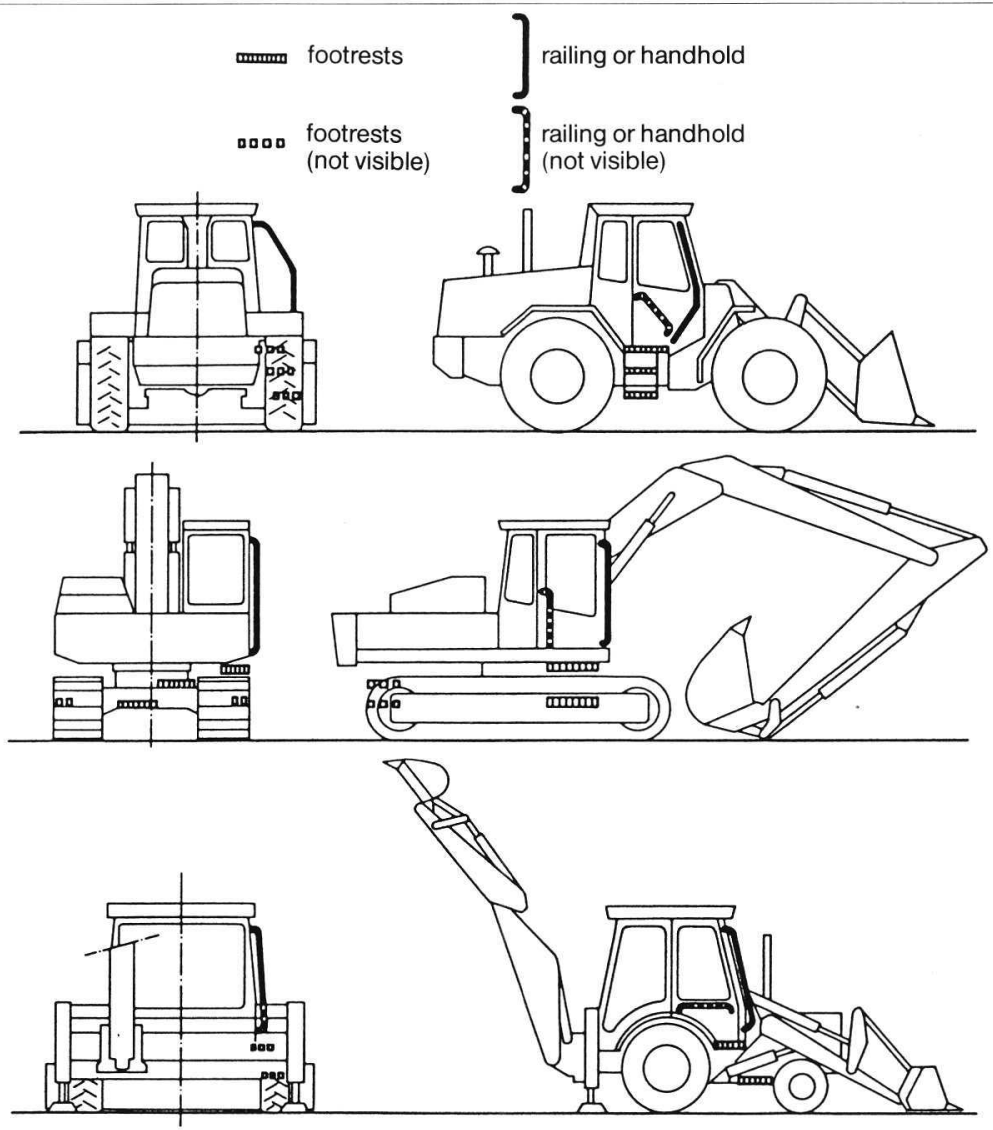

Fig. 2.1.a.

Access routes and provisions of the wheel-loader, the hydaulic excavator and the back-hoe loader. 


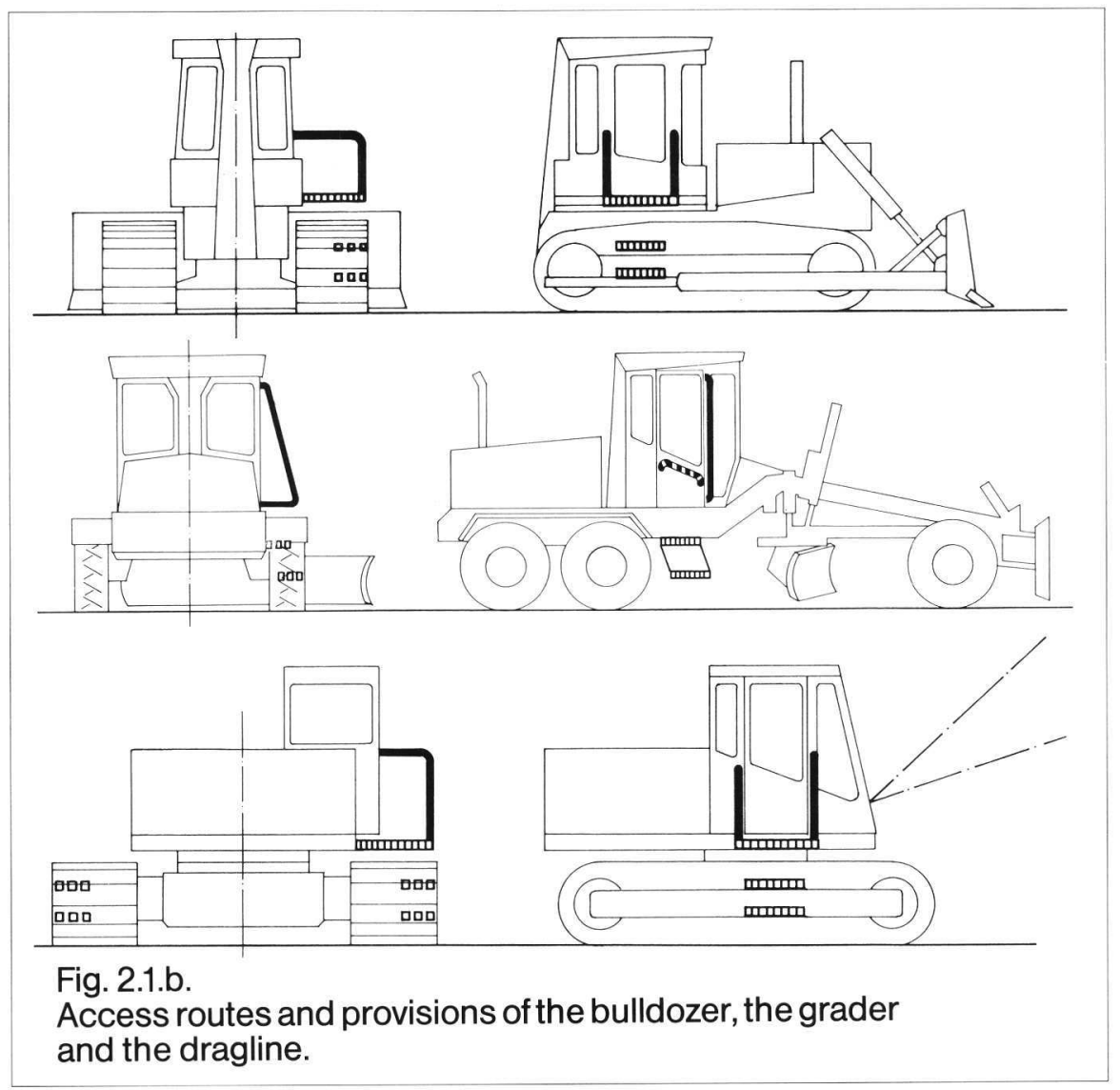

\section{Access routes to cabins}

- The access route should at least have reliable vertical climbing facilities, guaranteeing three-way support of the operator at all times.

- If the door opening has a height of less than $1700 \mathrm{~mm}$, immediately outside the cabin, a small platform, or an enlarged stairtread $(350 \mathrm{~mm} \times 350 \mathrm{~mm}$ ) should be fitted permitting the operator to stand up straight on which he may turn around to descend rearwards. If a hinged outward opening door is fitted for access by the operator while standing on the platform, the platform should be of sufficient dimension to permit the operator to retain an area of at least $350 \mathrm{~mm} \mathrm{x}$ 
$350 \mathrm{~mm}$ on which to stand while freely opening the door.

- A horizontal access route across the chassis or the wheel arches is recommended, when this results in improved vertical entry facilities.

- The entry route should avoid obstacles which cause unnecessary or dangerous climbing, as much as possible. High thresholds in backhoe-loaders, and any access route crossing the bucket, as in the case of wheel-loaders with the entrance at the front, should be avoided.

- In the event that entry to a wheel-loader is designed at the front, between the lifting mechanism, the access route should be across one of the booms and not across the bucket or the blade. In terms of safety, the entry route must be at least blocked by a door or bar, until the lifting or tipping mechanism of the shovel rests on the ground.

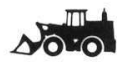

\section{Access facilities, general aspects}

- In terms of being able to enter or leave a cabin quickly, conveniently and safely, stairs are to be preferred to steps or ladders.

- The first stair tread or rung should preferably be no more than $400 \mathrm{~mm}$, and certainly not more than $600 \mathrm{~mm}$ from ground level. If the ground clearance factor makes this necessary, this part of the vertical entry should be mounted flexibility or be automatically movable. If the lowest rung is automatically movable, it should be possible to mount only, when the handbrake is on.

- Footrests should be anti-slip and, where possible selfcleaning, on account of the possible presence of clay or mud, and often of oil and grease on shoes.

- On both sides of the vertical entry, at suitable locations, grips or handholds should be present, providing adequate support when standing up straight, on each rung.

- Horizontalaccess routes should preferably be $600 \mathrm{~mm}$ wide, providing free and safe passage, without the need of side railings. If the passageway is unavoidably narrower, on account of the structure of the appliance, the passageway in any event should not be narrower than $300 \mathrm{~mm}$, and a safety railing should be fitted on 
one side to prevent falls.

- Walkways should have self-cleaning and anti-slip grids, placed slightly higher than the chassis or the wheel arches, ensuring a self-cleaning effect.

- Stairs, platforms and railings must be able to withstand the harsh environment of earthmoving activity, and it should be possible to replace these simply and conveniently, where necessary.

\section{Doors}

- Where the height of the cabin makes it necessary to stand on stairs or on a ladder to open the cabin door, outward opening doors should be avoided.

- The configuration of the cabin door should be such that unobstructed passage is possible, without danger of injury by projections. The width of the door opening should preferably be $600-800 \mathrm{~mm}$. This width, to a height of $770 \mathrm{~mm}$ above the cabin floor, should not be less than $300 \mathrm{~mm}$, and above a height of $770 \mathrm{~mm}$ the width should not be less than $450 \mathrm{~mm}$.

- Doorhandles of sliding doors should have a vertical grip. The height - measured from the place where one stands when opening the door - to the doorhandle, should preferably be $900 \mathrm{~mm}$. In the case of sliding doors this height, in connection with the force to be exercised, should be $1500 \mathrm{~mm}$ maximum, and $800 \mathrm{~mm}$ minimum. In case of a hinged door the height to the doorhandle should be $1500 \mathrm{~mm}$ maximum (standing at ground level $1700 \mathrm{~mm}$ maximum) and $500 \mathrm{~mm}$ minimum.

- A wide open door must have a smoothly operating, automatic latch system, which can be conveniently unlocked, while seated in the cabin. The latch should remain reliable, preventing sudden slamming of the door, even after years of use. Rubber snap locks for latching should be avoided.

- A hand grip must be fitted on the inside of hinged doors, on the hinged side, to enable the operator to close a $180^{\circ}$ open door. Doors which may fall shut, on account of their weight and being fitted at an angle - as is the case with some wheel loaders with an entrance at the front - must be equipped with a spring mechanism which balances the door weight.

- The doorhandle, handholds if any, and the unlatching mechanism on the inside of the door, must be designed in such a way that these do not present possible 
injury to the operator, while operating the controls of the machine.

- Closed doors must not obstruct outward visibility and ventilation.

- The windshield or the roof window and - in the wheel loaders with the entrance at the front, the back window - should be designed as emergency exits. Their minimum dimensions in relation to the cabin dimensions should be: width $560 \mathrm{~mm}$, length and height $310 \mathrm{~mm}$.

- For further details of the design of stairs, ladders, railings and doors, reference is made to the standard ISO 2867 and the relevant chapters in the Dutch standard for mobile cranes (NEN 2027). 


\section{Outward visibility}

The view that an operator should have from the cabin during earthmoving operations, plays an important part in the design of the machine, the cabin, and the seating arrangements. Next to a good view of the moving equipment, such as the bucket, the digger, blade or other moving equipment, good visibility to the sides and to the rear, when slewing or reversing, is important. Obstacles or persons on the site, in front of, next to or at the rear of the machine, must be watched closely.

It is recommended that an audible signal will automatically be given while reversing.

When being driven on public roads, the cabin arrangements in terms of visibility, should conform to the road traffic ordinance.

Because of the operator being subjected to vibration and shocks, while driving wheel-loaders, bulldozers, graders and back-hoe loaders, contorted body positions should be reduced to a minimum, by fitting inside and/or outside mirrors, or by installing a CCTV camera and monitor.

In terms of the survey targets, the following remarks and conclusions are relevant.

- Regarding the field of vision of the operator of an earthmoving machine, while driving or performing earthmoving activities, distinction is made between three aspects:

\section{Field of vision A:}

the forward view of the operator in a normal seated position, moving his head and eyes only within the limits of comfort. This field of vision covers a pyramid-shaped area forward. The top of the pyramid coincides with the reference point of the operator's eyes*. The pyramid is flanked by planes, the positions of which are shown in fig. 3.1.

* The point between the two eyes. The location of the reference point in the cabin depends on the height of the operator and on his seated position.

\section{Field of vision B:}

the view of the operator to the sides and behind the machine, in a normal seated position, using inside and outside mirrors, or a CCTV monitor, placed within field of vision $A$ (see fig. 3.2). 


\section{Field of vision C:}

the view the operator can obtain, by moving the torso, head and eyes within the maximum movement range. This field of vision is pyramid-shaped, to the sides and the rear of the operator. Their tops coincide with the reference point of the eyes. The pyramid is flanked by planes, the positions of which are shown in fig. 3.1.

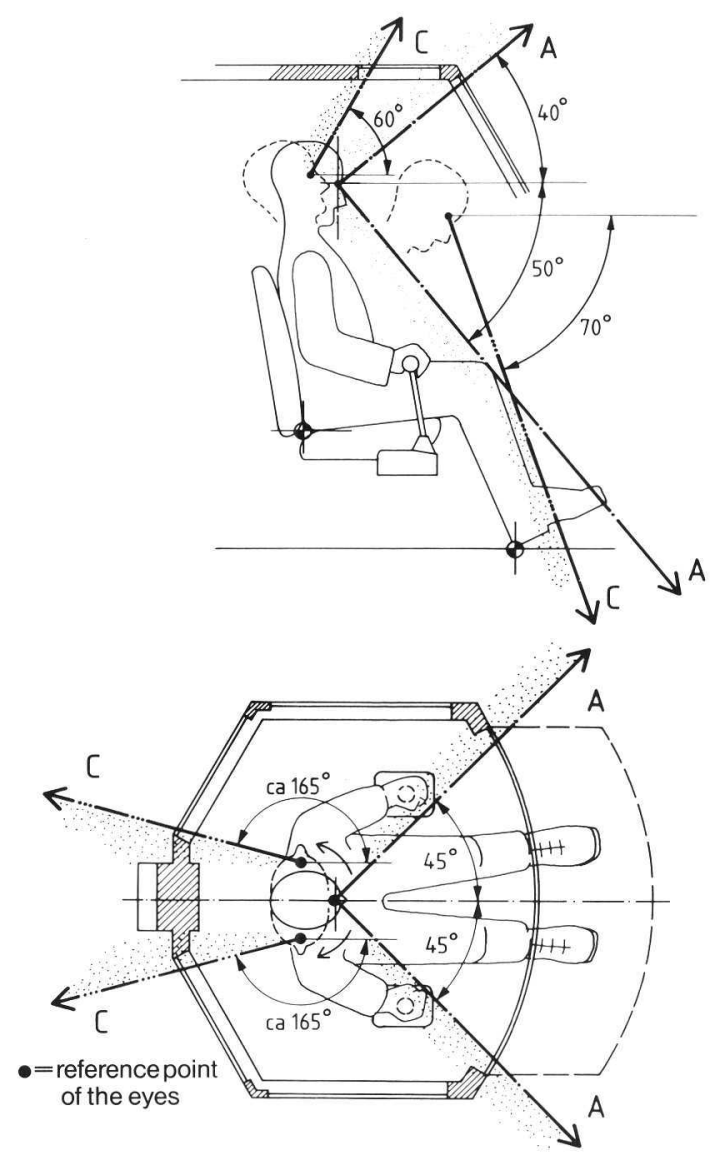

Fig. 3.1.

Fields of vision $A$ and $C$ in a vertical, respectively horizontal plane, through the reference point of the eyes 

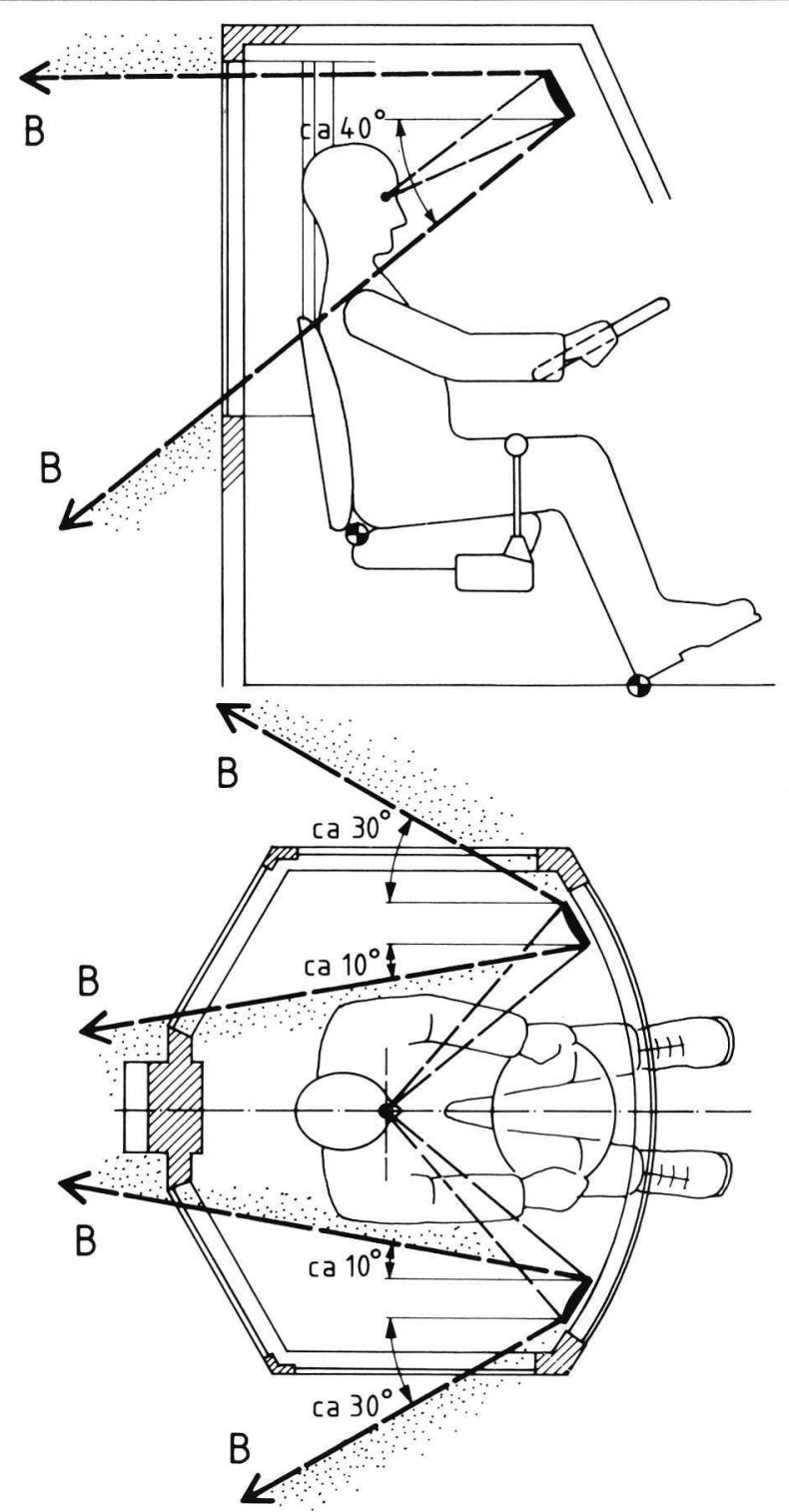

Fig. 3.2.

Field of vision B in a vertical, respectively horizontal plane, through the middle of the inside mirrors (for this illustration a safety cabin of a wheel-loader, bulldozer or grader was used) 


\section{In respects of fields of vision $\mathrm{A}, \mathrm{B}$ and $\mathrm{C}$, the following requirements apply for the viewin general, or the visibi- lity of objects or persons in particular (see also fig. 3.3).}

\section{Type of machine}

Wheel-loaders

Back-hoe loaders (front)
Hydraulic excavators Back-hoe loaders

(rear)

Dragliner

\section{Bulldozers} Graders

\section{Requirements in field of vision A}

In addition to the site and the route followed by the machine, at least both extreme corners of the bucket must be visible, within its manoeuvring area, from the levelling position, to the dumping position, at the highest limit of the boom

Next to a full view of the site and the route to be followed by the machine, at least the prongs of the bucket should be visible throughout the complete range of field of vision $A$. In the case of a horizontally slewing boom: also the full horizontal range of field of vision $A$.

Next to a full view of the site and the route to be followed by the machine, at least the two extreme blade points on the cutting line of the bulldozer, resp. grader blade and the ground should be visible.

\section{Requirements in \\ field of vision $B$}

Next to a panoramic view of the site and the route behind the machine, also while turning, at least the extreme ends of the chassis of the wheel arches at the rear of the vehicle, should be visible. Traffic from the rear or overtaking vehicles, should be visible, at actual size, in the mirrors.

In the case of slewing superstructures; with one or more mirrors, blind spots to the sides of the superstructure should be prevented, and at least the extreme ends of the rear of the superstructure should be visible. In the case of hydraulic excavators also: the blind spot at the front, next to the boom, should be obviated for example when digging ditches.

Good panoramic visibility of the site and of the route behind the machine is required. In addition to the above the requirements laid down for the wheel-loader should also be applied for the grader.

\section{Requirements in \\ field of vision C}

The full range of any moving equipment fitted, must be visible, as well as persons or objects immediately next to the machine.

The extreme ends of the bucket, the jib or the boom must be visible, even at extreme high or low positions of the hoist mechanism. This also applies to the extreme ends of the tracks (front) and to persons or objects immediately next to the machine.

The extreme ends of the machine must be visible, as well as the area of operation of moving equipment mounted on the rear of the vehicle.

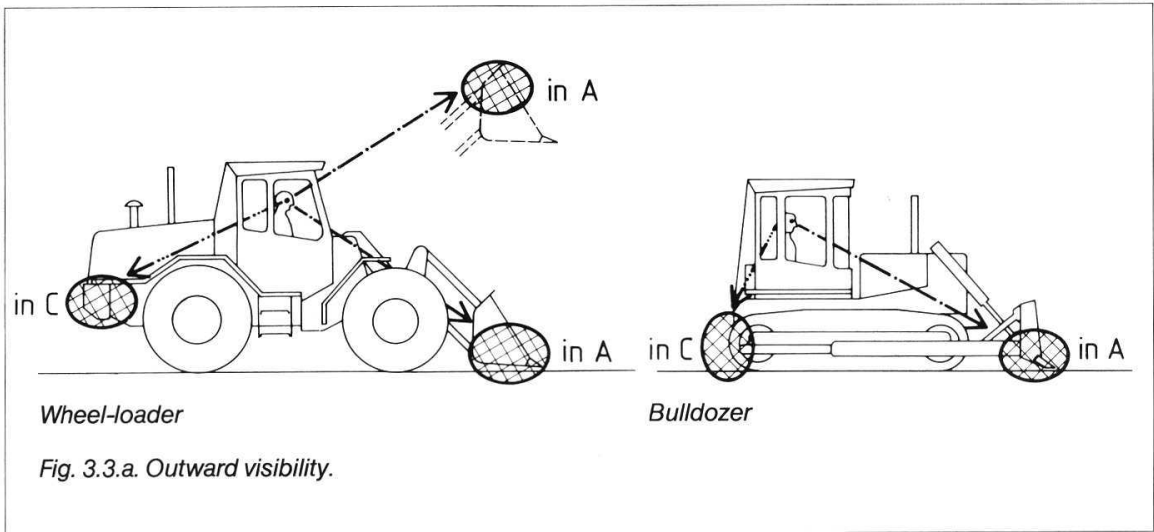



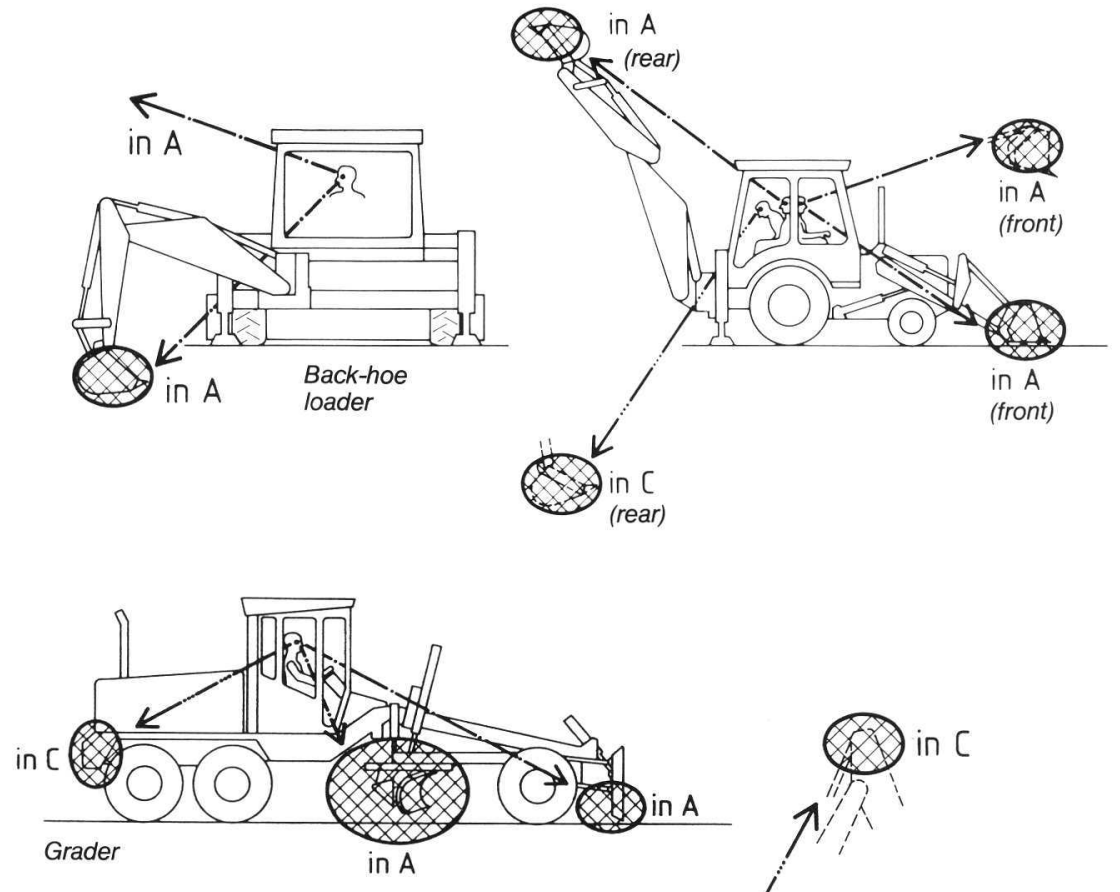

Fig. 3.3.b. Outward visibility.

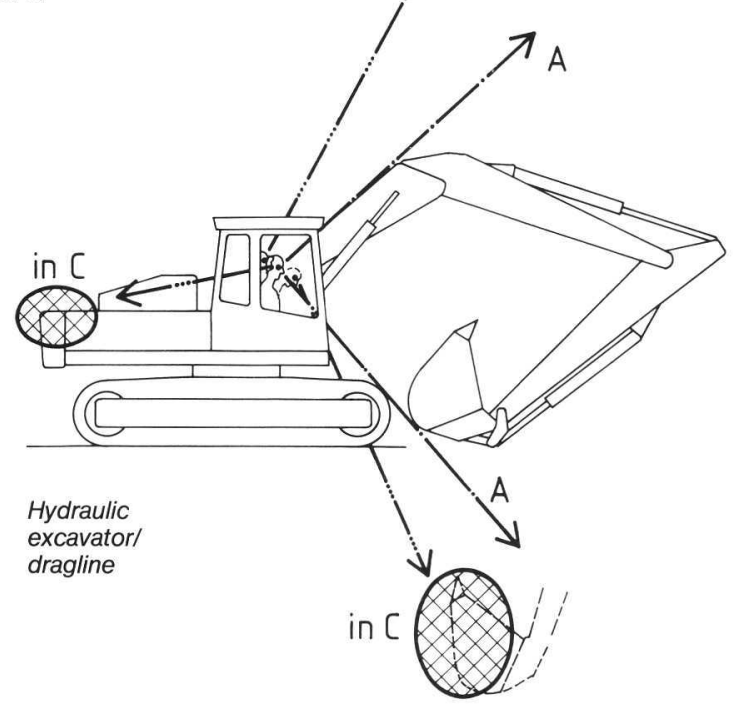


Measures which improve the view in fields of vision $A$ and $\mathrm{C}$ while looking forward, are:

\section{Wheel-loaders, front of back-hoe loaders, bulldozers}

- raised position of the cabin on the chassis

- location of control and instrument panels in such a manner, that these do not obstruct outward visibility

- the fitting of a panoramic windshield, or a type of window close to it, by means of several flat windowpanes with as few frames as possible, of minimum width in the direction of view.

- reducing the distance between the eye reference point and the cabin windows.

- a construction of cylinders and hinge points of lifting and tilting systems in such a way, that the sides of the shovel or the blade remain visible at the lowest position of the mechanism, through a narrow aperture

- locating the cabin as far forward as possible on the chassis; on articulated wheel-loaders preferably on the front section

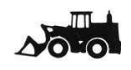

- rearward sloping construction of the front wheel arches

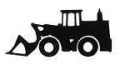

- making holes in the top of the bucket so that the prongs of the bucket are at least partly visible

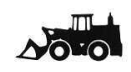

- the narrowest possible construction of the front of the engine housing

- downward extension of the front window next to the engine housing

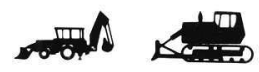

\section{Hydraulic excavators, draglines}

- greatest possible downward extension of windows

- locating control and instrument panels in such a way that these do not obstruct outward visibility

- fitting a small window in the floor or the side of the cabin, on the side of the boom or the jib, so that the 
bucket remains in view close to the machine, when deep pits are being dug

- increasing the distance between the cabin on the superstructure and the centre of the turntable

\section{Rear of back-hoe loaders}

- using a panoramic rear window, or using several flat windows, if the boom can be slewed

- using a slide for sideways movement of the excavating system at the rear

- higher location of the cabin on the chassis

- higher position of the operator's seat in the cabin, or extending the horizontal adjustment of the seat towards the rear window.

\section{Graders}

- fitting windows down to the cabin floor on both sides of the chassis beam

- reducing the width of the chassis beam

- locating the control panels on both sides of the seat, or fitting an adjustable panel in the centre of the cabin, permitting the controls to be located above the upper legs.

Measures which improve the view in fields of vision $B$ and $\mathrm{C}$, towards the rear and sides, are:

Wheel-loaders, bulldozers, graders

- higher location of the cabin on the chassis

- reducing the distance between the eye reference point and the cabin windows

- placing heavy-duty roof frames, width $<200 \mathrm{rnm}$, of a ROPS construction (ISO-3471), directly behind the head of the operator or, if so required, at the corners of the cabin, where field of vision $\mathrm{C}$ merges into field of vision $A$.

- fitting a CCTV camera as high as possible to the rear of the cabin, and a monitor on the instrument panel. The monitor should provide a panoramic view to the rear, including the area immediately behind the rear wheels.

- placing the cabin on the front section of an articulated wheel-loader, so that during reversing in corners, the operator can look behind without body contortions.

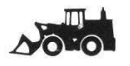


- panoramic rearwindow, or severalflat windows behind the operator's seat, in wheel-loaders

\section{$\Delta$ o:}

- using forward sloping rear wheel arches

\section{$\Delta$ o:}

- an engine housing which reduces in size upwards and towards the rear.
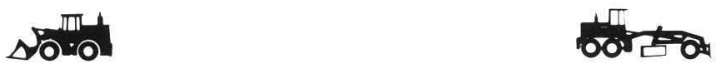

\section{Hydraulic excavators, draglines}

- when a low engine housing on the superstructure is not possible, the location of the cabin in respect of the engine housing to be higher

- when the engine housing is as high as the cabin, the cabin should be located to the side of the superstructure, permitting visibility to the rear, through a narrow rear window

- for visibility when slewing, a CCTV camera can be located at the top rear of the cabin, with a monitor inside the cabin.

\section{Front of back-hoe loaders}

- higher location of the cabin on the chassis

- locating the frames of a ROPS construction (see ISO3471) in the symmetrical plane between the two seat positions in front and in the rear of the cabin.

\section{Other general recommendations}

- mirrors should be vibration-free and adjustable

- panoramic mirrors within the cabin are less sensitive to damage

- inside mirrors should be at least $125 \mathrm{~mm}$ high and $250 \mathrm{~mm}$ wide, slightly convex, radius $600-1000 \mathrm{~mm}$, providing a good panoramic view. The distance from the eye reference point to the inside mirror should not be greater than $750 \mathrm{~mm}$, at the rearmost position of the seat.

- outside mirrors should be at least $150 \mathrm{~mm}$ wide and $300 \mathrm{~mm}$ high and strong enough to withstand the conditions of the construction environment (e.g. hinged adjustable and fitted with a return spring). 
If the vehicle is also to be used on public roads, the mirrors should at least have a partly flat surface, and be able to reflect traffic from behind at actual size

- in connection with the risk of damage outside working hours, it should be possible to replace these mirrors simply, and these should have a position indicator, enabling the operator to adjust the mirror without assistance from other persons

- mechanically driven windshield wipers on front and rear windows are essential, and these should cover the greatest possible area of these windows (parallel movement), including at least the full field of vision $A$, and those areas of fields of vision $B$ and $C$, guaranteeing a view of persons or objects close to the machine, through the inside and outside mirrors

- sunvisors of a transparent type should be fitted to cover the area above the horizon in field of vision $\mathrm{A}$. Shields, slides or curtains must not be fitted to opening parts of a window and must be non-reflective, in order to avoid parts of cabin or panels to be mirrored. It is also recommended that the cabin interior be covered with non-reflecting dark materials

- all windows must be able to be blown by warm demisting air

- if roof windows are used, it should not be possible that rain water remains standing on these

- window panes must be made of scratch resistant safety glass. 


\section{Seating accommodation}

These recommendations proceed from the principle that the operator must be able to do his work seated, and not standing. Both in order to avoid unnecessary fatigue and to improve control accuracy, it is important that the seating is designed in such a manner, that one can conveniently observe all points within field of vision A (see chapter 3) for long periods, while comfortable and accurate control, with both hands and feet, remains guaranteed. This is especially important when the operator's seat is equipped with devices which absorb low frequent vertical vibrations and shocks. In spite of large amplitudo's that may occur in the damping mechanism, contact with the operating controls may not be lost. Furthermore, the seat must be adjustable, so that it will fit both large and small operators. It is difficult in technical terms, and economically unattractive, to design cabins in such a way that these will be suitable for all physical sizes. Consequently this brochure will consider the physical sizes of $90 \%$ of the male population, which corresponds with $50 \%$ of those of the female population as well.

The seat should offer adequate support to the body, particularly in view of any violent lateral shocks and vibrations that may occur. These recommendations relate closely to those of the chapters "Outward visibility" and "Vibration and shocks". The following general remarks refer:

- A reference point SP can be defined, being the intersection of two lines through the centre of the occupied seat, where back and thighs touch respectively the backrest and the seat bottom. The back of the heel, resting on the pedal or the floor, is called the heel reference point HP (see fig. 4.1).

- The seating accommodation should be designed in such a manner that it is suitable for operators having a build between that of a small (5th percentile), and that of a large (95th percentile) male. The dimensions must agree to those of standard ISO-3411. 


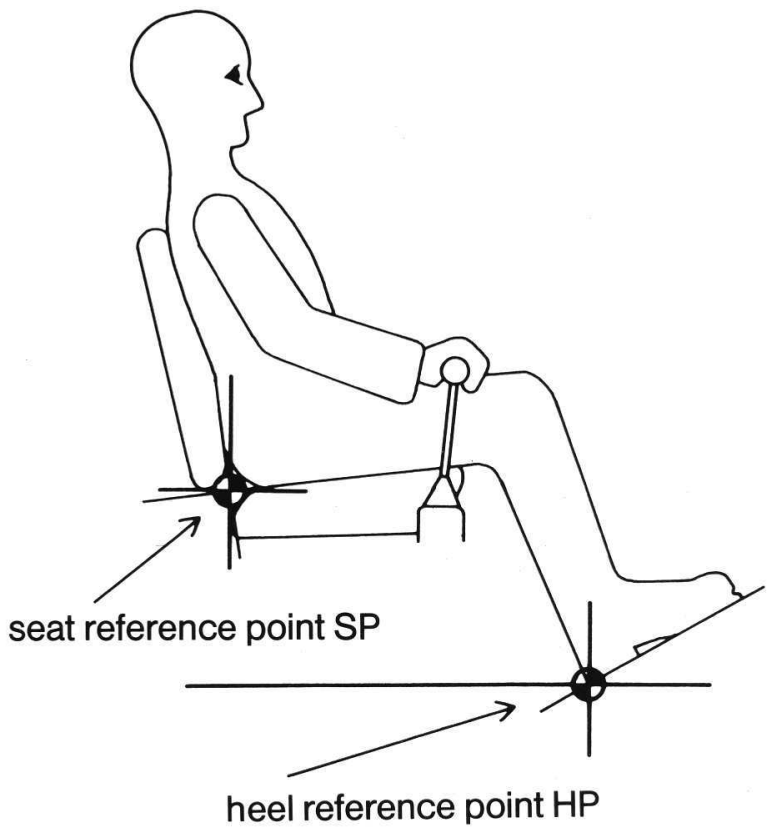

Fig. 4.1.

Seat reference point and heel reference point

Two types of operators' seats will be dealt with:

Standard operator's seat (see fig. 4.2.)

This adjustable seat may be equipped with a spring damping mechanism with modest spring travel (max. $+/-35 \mathrm{~mm}$ ). The seat has a wide range of applications and it can be used in most machines which are subjected to a low level of shock and vibration. The controls for the moving equipment are not incorporated in the seat adjustment. If so required, armrests can be fitted.
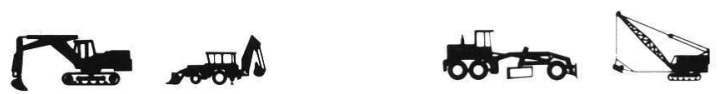

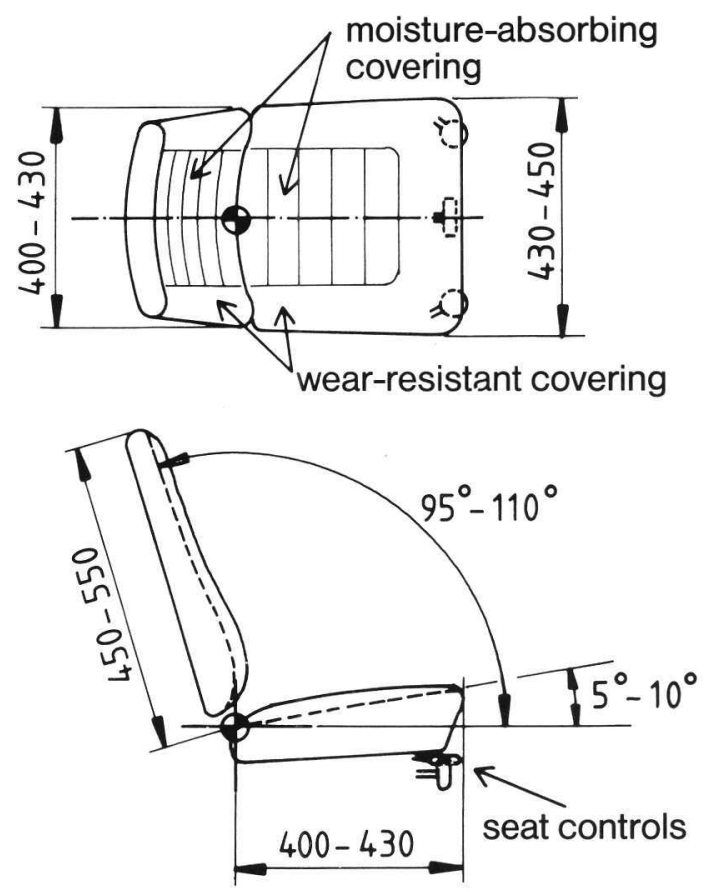

Fig. 4.2. Standard operator's seat.

Special operator's seat (see fig. 4.3.)

This adjustable seat is equipped with a spring damping mechanism with relatively long spring travel (max. $+/-75 \mathrm{~mm}$ ) and with cushions and armrests, which provide extra support to the body and elbows, in conditions where considerable lateral or vertical acceleration may occur. The spring damping mechanism may be of the passive variety (non-servo controlled), or it may be an active (servo controlled) pneumatic or hydraulic system, and it should at least meet the conditions of chapter 10 "Vibration and shocks". The controls for the moving equipment should be mounted on the seat structure, and 
these should move with the seat when this is adjusted and with the spring travel of the seat bottom.
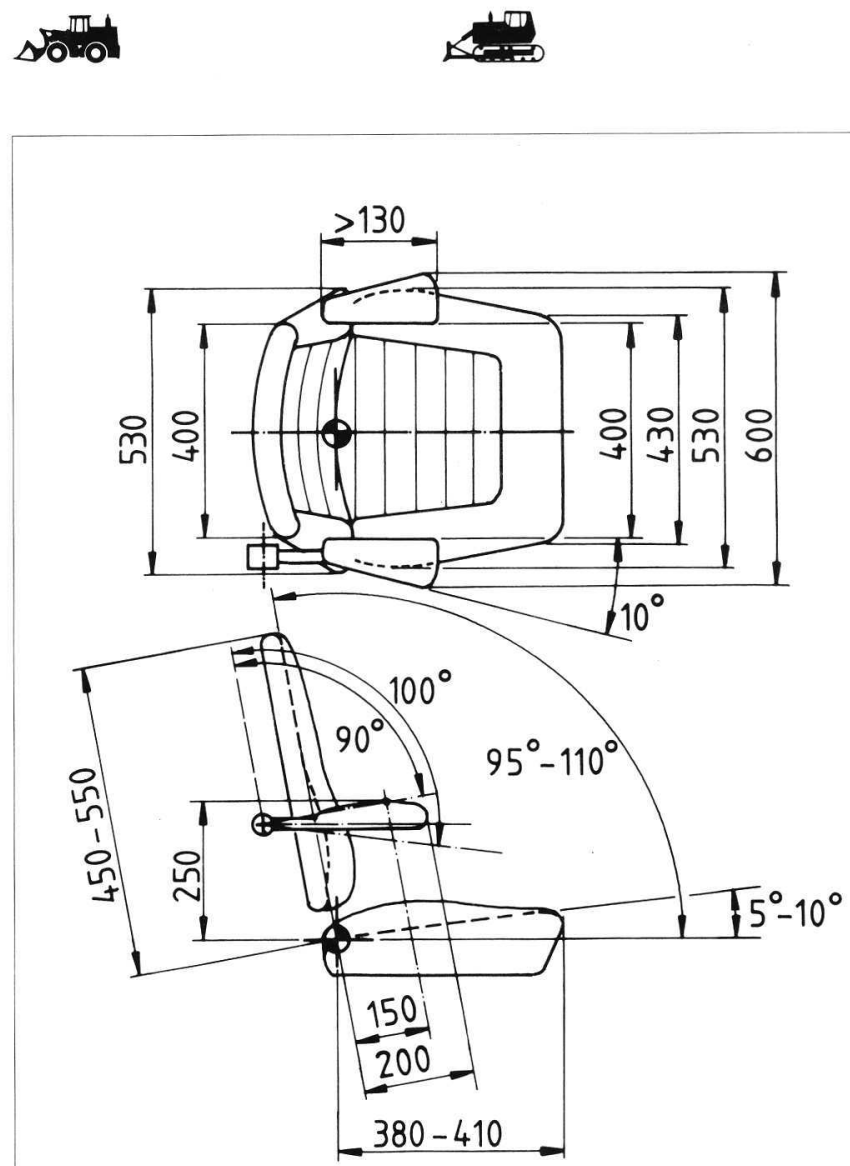

Fig. 4.3. Special operator's seat

For the seat dimensions and adjustment in respect of the $\mathrm{HP}$, the following specifications apply: 


\section{Seat bottom}

- seat width

- depth of seat measured from SP

- rearwards inclination adjustable between

- height adjustment from SP to a horizontal plane through HP (excl. spring travel)

- length adjustment from SP to a vertical plane through HP

- maximum spring travel

\section{Seat back}

- width of seat back

- height of seat back, measured from SP

- angle between seat back and horizontal plane

\section{Armrests}

- length to the intersecting plane of back and seat back through SP

- angle adjustment in respect of a parallel plane to the intersecting of back and seat back through SP

- distance from the highest position of the unoccupied seat cushion to the same plane through SP

- distance from the highest position of the unoccupied seat cushion to a horizontal plane through SP

- length of the cushions

- distance between the cushions of the left and the right hand armrest: inside outside standard seat

$$
\begin{array}{cc}
430-450 \mathrm{~mm} & 430-530 \mathrm{~mm} \\
400-430 \mathrm{~mm} & 380-410 \mathrm{~mm} \\
5-10^{\circ} & 5-10^{\circ}
\end{array}
$$

$350-425 \mathrm{~mm}$

$325-400 \mathrm{~mm}$

$550-700 \mathrm{~mm}$

$550-700 \mathrm{~mm}$

$+35 \mathrm{~mm}$

$-35 \mathrm{~mm}$

$+75 \mathrm{~mm}$

$-75 \mathrm{~mm}$

$$
\begin{array}{cc}
400-430 \mathrm{~mm} & 400-530 \mathrm{~mm} \\
450^{\star}-550 \mathrm{~mm} & 450^{\star}-550 \mathrm{~mm} \\
95-110^{\circ} & 95-110^{\circ}
\end{array}
$$

** $90-100^{\circ}$

$150 \mathrm{~mm}$

$250 \mathrm{~mm}$

$>130 \mathrm{~mm}$

$\min .400 \mathrm{~mm}$

approx. $600 \mathrm{~mm}$

* when backwards looking is frequently required.

** if armrests are required, the measurements given for the special seat can be used. 


\section{Other recommendations}

- the seat must have rather firm cushions, with a heatinsulating, wear-resistant and ventilating covering. The cushions should be softer, if it cannot be avoided that high frequency vibrations of the engine or the transmission are transferred through the seat frame. The backrest and the seat cushion must be shaped anatomically, with an adequate, if necessary adjustable, support for the lower back.

- Headrests need only be fitted in case of violent rocking or shocks during operations.

- Sprung seats should at least have an adjusting mechanism for the weight of the operator (500 $1100 \mathrm{~N}$ ), unless an automatic weight adjustment has been incorporated.

- In safety cabins (ROPS construction according to ISO 3471) a safety belt must be fitted. The belt should be of the inertia type, and fitted to the seat structure. Except in the case of the machine rolling over suddenly, the safety belt must be able to hold the hip and torso in position, during sudden upward, lateral or forward and rearward movement while driving in rough terrain (see also ISO/DIS 6683).

- All seat adjustments must be possible to be effected without using tools, and from the seated position.

- In bulldozers it is recommended to design the seat with the operating controls in such a way that it can be rotated in the horizontal plane over $15^{\circ}$ both to the left and to the right. It is necessary that the seat can be fixed in any position.

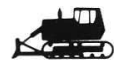

- For back-hoe loaders, having an operating position both in the front and the back of the cabin, the above requirements apply to each operating position individually. In the case of limited length of a cabin the seat should be capable of being swivelled through $180^{\circ}$. If the cabin is of adequate length, two separate seats must be incorporated, providing good downward visibility at the back, with each seat as close as possible to the window.

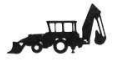




\section{Cabin dimensions}

The basic dimensions for the clear space required for the operator in the cabin are partly based on the standard ISO 3411.

- The minimum clear width of the cabin interior must be $920 \mathrm{~mm}$. In very few isolated cases, where a machine is in operation only a few hours per day - such as in non-articulated wheeled shovel loaders or in very small hydraulic excavators, the cabin may be narrow$\mathrm{er}$, but in no case less than $750 \mathrm{~mm}$. In such instances special attention must be paid to the location of the operating controls.

- The height of the cabin must be such, that a large operator (95th percentile, see standard ISO 3411), wearing a helmet, and at the highest seat position, must have adequate headroom. This height should be at least $1070 \mathrm{~mm}$ above the seat reference point (SP) at the top spring stroke of the seat adjusted in the highest position. These minimum dimensions also apply in the case of open front or rear windows, when such a window, including its fittings, is opened against the roof.

- The front of the cabin wall or of any structural parts fitted to the inside front wall, must leave adequate space for a large operator to be able to stretch his legs. The distance from the front of the cabin, at the level of HP shall be a minimum of $400 \mathrm{~mm}$. From the centre line of a brake or clutch pedal, operated by the ball of the foot, the distance to the front of the cabin, or the aforementioned structural parts, should be $150 \mathrm{~mm}$.

- The distance from the rear wall of the cabin, or from the reinforced rear safety-structure frames, to the head of the large operator (95th percentile, see ISO/DP 3411), seated in the rearmost position, should be a minimum of $200 \mathrm{~mm}$. This does not apply to back-hoe loaders.

- The cabin should preferably include some storage space, with an automatically locking lid, for tools. A first-aid kit and a fire extinguisher (at least $7 \mathrm{~kg}$ for adry powder extinguisher), must be fitted firmly, so that these cannot become dislodged by shocks or by the machine rolling over. A provision for the hanging of clothing should also be included.

- A lockable storage cabinet for documents, manuals, 
personal effects, foodstuffs etc. mustalso be provided.

- Nextto, or between the pedals, anti-skid surfaces must be fitted, inclining upwards and forwards at an angle of $20^{\circ}$ from the horizontal, in such a manner that the feet can rest on these comfortably.

- The finish of the cabin should be such that one cannot easily bump into the steering wheel and housing, the cabin structure, gear lever, panels, handholds etc. Sharp projecting parts, such as doorlocks, must also be avoided.

- If work with earthmoving equipment is being done, whereby there is a risk of objects falling onto the cabin roof, the cabin should be designed in a manner which meets the requirements of the standard ISO 3449 (FOPS).

- Cabins of wheel-loaders, graders, bulldozers and back-hoe loaders must have a sturdy construction, which protects the operator in the event of the machine rolling over. This construction should meet standard ISO 3471 (ROPS).
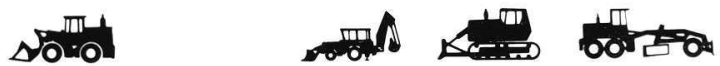

- In back-hoe loaders with a seat moving through $180^{\circ}$, there should be legroom of $200 \mathrm{~mm}$ while turning, between the front of the seat cushion in the foremost position, and the vertical plane of the wheel arches of the rear wheels. There must be room for the feet of at least $300 \mathrm{~mm}$.

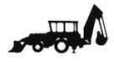




\section{Operating controls}

In addition to the requirements regarding the location of operating controls in the most comfortable areas, such as those of standard ISO 6682 (see fig. 6.1.), further recommendations are also important.

These recommendations also relate to additional requirements, as a consequence of visibility, springing and damping of the seat, cabin dimensions, the use of safety belts which may limit the freedom of movements and possible necessary extra stabilisation of the work posture by the feet. The starting point is a cabin which is placed in the centre, or left of centre, of the chassis or superstructure.

\subsection{Operating controls for driving}

The layout of the operating controls for driving should be seen in conjunction with those for the operation of the moving equipment (bucket or blade), lifting- and digging arm, boom, jib or slewing gear.

\section{Machines with steering wheel}

(see also fig. 6.1 and 6.2)

- The steering column should form a sharp angle $(\alpha)$ to the horizontal towards the driver; this angle should have the following value:

wheel-loaders, wheeled

hydraulic excavators

back-hoe loaders (with steering knob) $\quad \alpha=20-25^{\circ}$ graders

$\alpha=50-60^{\circ}$

- The diameter of the steering wheel must be 350 $400 \mathrm{~mm}$. In the case of a machine with indirectsteering, a rotating spherical handhold should be fitted on the steering wheel (diameter sphere: 35 - $45 \mathrm{~mm}$ ).

- The knees of the large operator (95th percentile - see standard ISO 3411) must be able to pass comfortably underneath the steering wheel and/or column, in terms of accessibility to the seat. For the location of the steering wheel in the cabin, the following requirements 


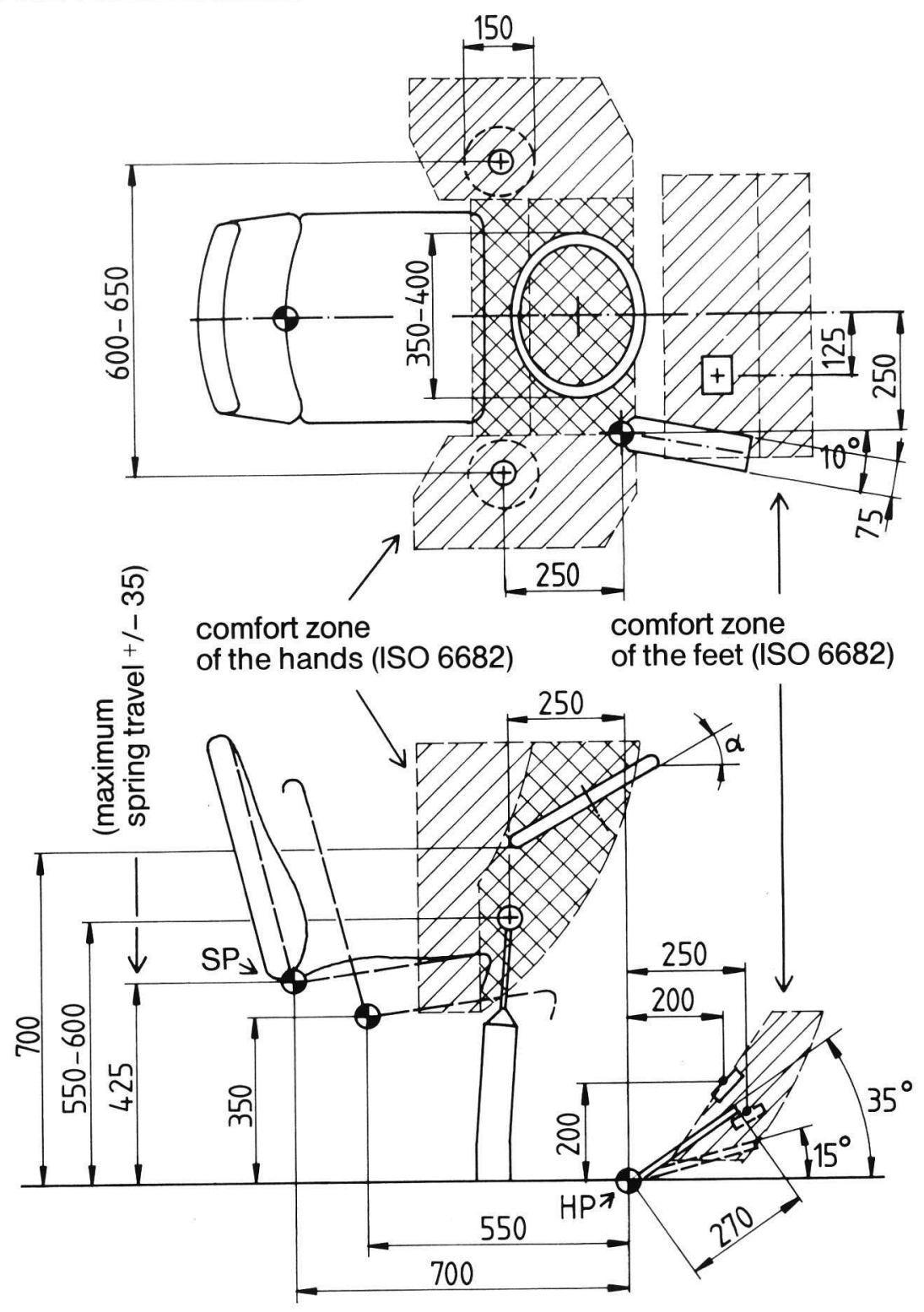

Fig. 6.1

Dimensions of the seat*;

adjustable seat, non-adjustable controls. 


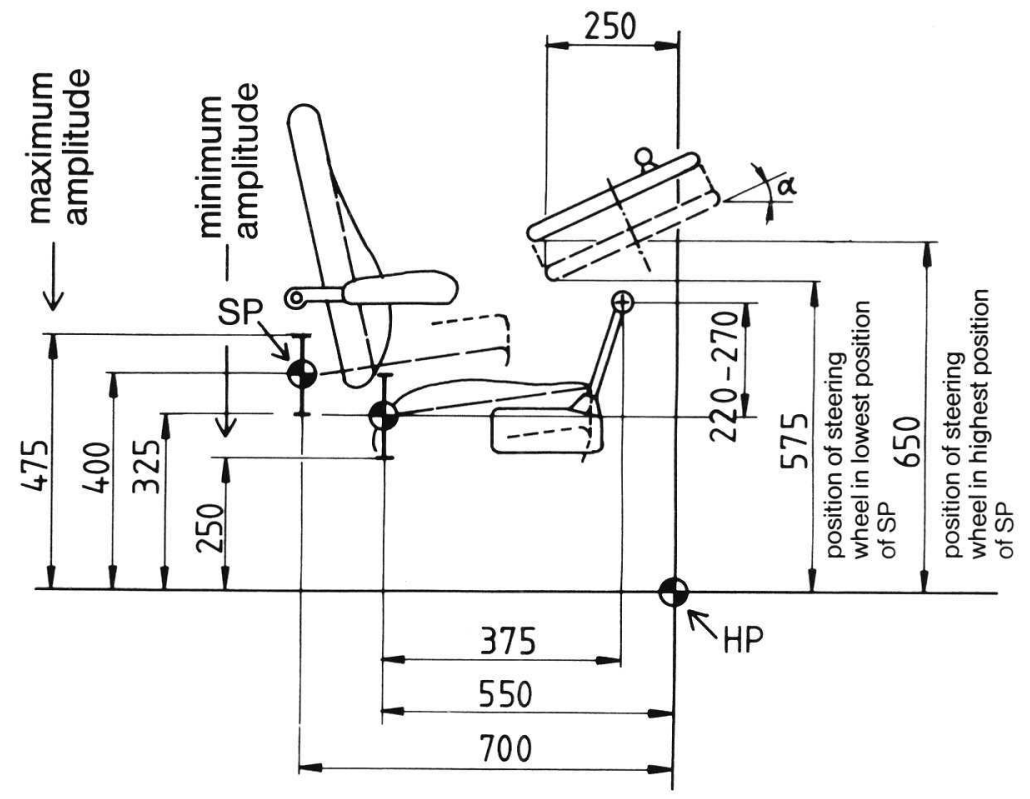

Fig. 6.2

Dimensions of the seat*; seat and operating control(s) adjustable, steering wheel height adjustable.

apply: the horizontal distance between the lowest point of the steering wheel and a vertical plane through $\mathrm{HP}$, should be $250 \mathrm{~mm}$. The vertical distance from that point on the steering wheel to a horizontal plane through HP, in the case of a standard seat, should be $700 \mathrm{~mm}$, and in case of a special seat, the steering wheel and any gear levers located immediately below it, should be height adjustable between 575 and $650 \mathrm{~mm}$.

- The gear change and the change of direction functions should preferably be combined in one selector lever. The control forces of this lever should be between 5 and $20 \mathrm{~N}$. The lever should be designed and located as follows: as steering column gear change on the left of the steering column in wheelloaders and back-hoe 
loaders; floor-mounted on a separate console left of the operator's seat in bulldozers and graders; to the right of the operator's seat in wheeled hydraulic excavators.

\section{$\Delta$ iria
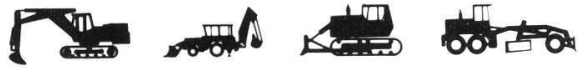

Machines with steering lever

- The directional control of tracked machines, or wheeled machines with swivel steering, should be executed as a cross-control lever. The direction of movement should coincide with the movement of the machine, in such a manner that during driving and manoeuvring, the moving equipment can also be operated; it may be necessary to install two double-operative pedals, which are automatically out of function when the lever is being operated.

\section{Pedals}

- The number of pedals should be limited to a minimum.

- In bulldozers, pedals should be omitted, enabling the operator to brace himself by means of special footrests against a forward inclination of the machine.

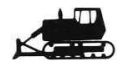

- The location of the pedals and their dimensions are shown in fig. 6.1. The pedals should be placed within the areas laid down in standard ISO 6682.

- The accelerator-c.q. decelerator pedal and the brake pedal should be placed right of centre of the cabin.

- The accelerator pedal and frequently used brake pedals, such as those of wheel-loaders and draglines should be exclusively foot-operated and their operation should be light and within comfortable angles of the ankle joint. The angle between instep and shinbone must not be less than $80^{\circ}$ and no greater than $100^{\circ}$; (air) powered operation is to be preferred.

- If possible the clutch should have automaticoperation.

- The control force of the pedals should be between 30 and $50 \mathrm{~N}$ for foot operation, and between 50 and $100 \mathrm{~N}$ for operation by foot and leg.

- In wheel-loaders, graders and back-hoe loaders, the accelerator pedal should have a raised edge enclosing the heel $(\mathrm{h}=10 \mathrm{~mm})$, in connection with heavy lateral swaying and shocks. The other pedals have self-cleaning surfaces.
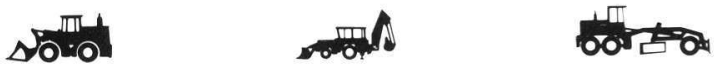


\subsection{Operating levers for earthmoving and slewing system, if present}

\section{Cross-control levers}

- It is recommended that cross-control levers be fitted for frequently used operating controls which also must be able to be worked in combination, according to the layout presented in fig. 6.3 (pages 40 and 41).

- For the location of cross-control levers in the cabin, the following requirements apply, in the case of:

a standard seat (see fig. 6.1):

- height from the grip to a horizontal plane through HP

$550-600 \mathrm{~mm}$

- horizontal distance from the grips in neutral position to a vertical plane through HP

$250 \mathrm{~mm}$

- horizontal distance between the grips of two crosscontrol levers in neutral position $600-650 \mathrm{~mm}$ a special seat (see fig. 6.2):

- height from the grips to a horizontal plane through SP

$220-270 \mathrm{~mm}$

- horizontal distance from the grips in neutral position to a vertical plane through SP

$375 \mathrm{~mm}$

- horizontal distance between the grips of the two cross-control levers in neutral position

$600-650 \mathrm{~mm}$

- The maximum movement of the levers should be $75 \mathrm{~mm}$ out of the neutral position (zero position) in all directions.

- The grips of the levers should be spherical (diameter of the sphere $35-45 \mathrm{~mm}$ ).

- The design of the levers should be such that a compounded movement can be achieved (e.g. 100\% digging boom velocity, combined with $50 \%$ slewing velocity). It is advisable to automatically link the engine rpm to the required power of one or more hydraulic systems, so that throttle operation during earthmoving activities becomes superfluous. When the levers are released, these should automatically return to the neutral position.
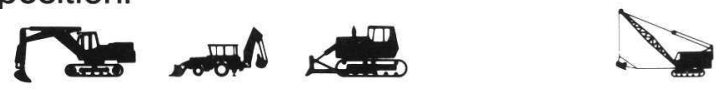
- The cross-control lever for operating the bucket and the lift boom should operate in such a manner that the lever may be released, when the lift boom or the bucket have been set in movement thus freeing the hands for driving. When the lift boom or the shovel has reached a predetermined position, the lever should automatically return to the inactive position.
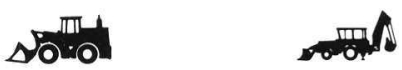

- The lift arm operation should have a floating position, for levelling with bucket or blade while reversing.
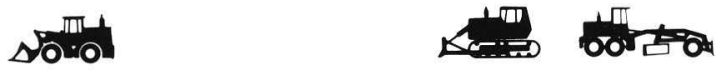

- The control force of cross-control levers should be a minimum of $5 \mathrm{~N}$ (artificial feel) and a maximum of $20 \mathrm{~N}$.

- The construction of the levers should be such that a hand resting on one of the levers does not effect activation. Unintentional touching of a lever should not result in movememt of the machine.

- The levers, and the panels or consoles on which these are mounted, should be located in such a way, that these do not obstruct accessibility to the seat, or outward visibility. If necessary, an adjustable or folding lever or console should be fitted.

\section{Other levers}

- If in special cases an extra control - such as for the operation of additional moving equipment - is necessary, this should preferably be placed to the right of the lever at the extreme right. In this case this lever should be longer than the cross-control lever. Less frequently used levers, for exemple those for the operation of the tracks, can also be located immediately next to the seat, between the cross-control levers and the seatback. In this case the levers should be shorter than the cross-control lever.

- Levers intended for just one function and which are moved forward and rearward, should have a maximum stroke of approx. $75 \mathrm{~mm}$ from the zero position. In this case a control force of $40 \mathrm{~N}$ is permissible.

\section{Other requirements}

- If the location of a lever on the door side cannot be avoided, it must be possible to fold it down to ensure 
good accessibility. The control function must be switched off automatically when the lever is folded down.

- On the slewing lever and/or the driving lever a pushbutton must be fitted for a separate horn.

- In the event of a foot-operated slewing brake being required, this should be placed immediately to the left of the centre of the cabin, in the area designated in standard ISO 6682.

- Pedals for the operation of moving equipment should be avoided. If this is impossible, these should operate in such a way that they can only be operated by a foot movement. Attention should be paid to a comfortable angle between shinbone and instep $\left(80-100^{\circ}\right)$. The control force should be between 30 and $50 \mathrm{~N}$. The pedale should also be located in the zone laid down in ISO 6682.

- Next to, or between the pedals there should be adequate space to rest the feet comfortably.

- The function of all operating controls should be shown clearly in the local language and/or with clearly recognizable symbols, in accordance with standard ISO/DIS 6405.

\section{Other operating controls}

- If operating controls are mounted on panels that must be reached while driving and wearing a safety belt, these should be within arm's reach. See also standard ISO 6682 for the areas of maximum arm's reach. 


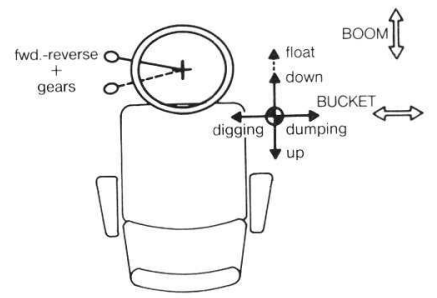

Wheel-loader, back-hoe loader (front)

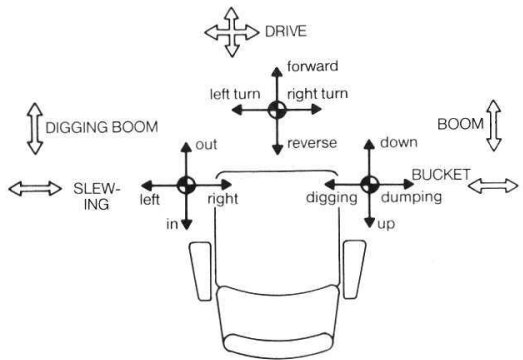

Hydraulic excavator,

back-hoe loader (rear)

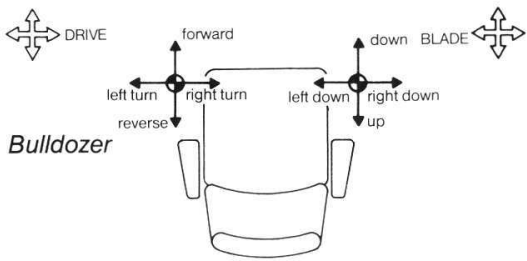

fig. 6.3.a. Patterns of operation 


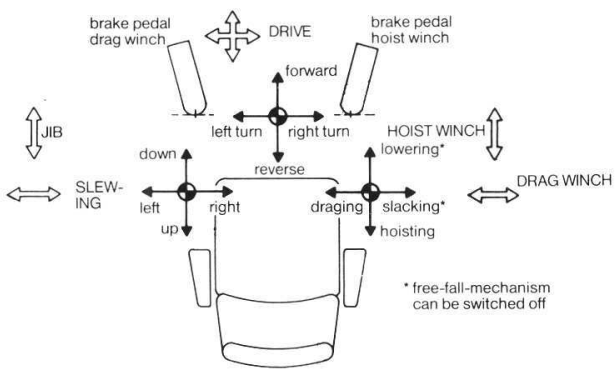

Dragline

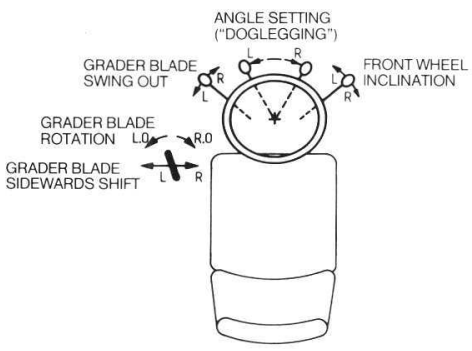

Grader: controls in movable steering colums

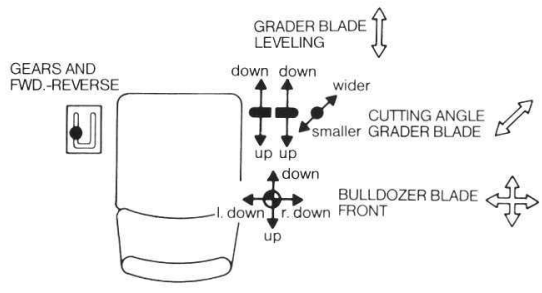

Grader: controls next to seat

fig. 6.3.b. Pattern of operation 


\section{Information presentation}

In addition to information presentation, particularly in respect of engine condition, drive and energy generating systems and driving, operating controls incorporated in the instrument panels, are also dealt with.

Next to the instructions which have been laid down in standards ISO 6011 and ISO/DIS 6405, regarding the necessary instruments, their lay-out in panels, instrument design and the symbols to be used, the following recommendations apply:

- Instruments, such as gauges, indicators and alarms, should be mounted in panels in front of, or next to the operator, preferably in field of vision A. These panels should be located in such a manner that these do not obstruct outward visibility unnecessarily.

- The instruments should bevisible, when the operator's hands are resting on the steering wheel or on the operating controls of the moving equipment.

- It is advisable to fit an audio or visual "central alarm" indicator, drawing the operator's attention, when the condition of the machine threatens to exceed the normal operating range.

- In back-hoe loaders an audio signal is imperative, as the machine is often operated with the seal facing the rear.

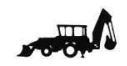

- If the cabin of an articulated wheel-loader is mounted on the front section, an indicator on the instrument panel should show the position of the rear section in relation to that of the front section.

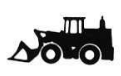

- A central alarm also makes it possible to mount instruments at other locations in the cabin than those mentioned. This may be useful in connection with the limited rooms available for a large number of gauges.

- Instruments should be grouped in an instrument panel that is at right angles to the direction of vision.

- All indicators, gauges or switches must have indications or symbols which clearly show their function (see standard ISO/DS 6405). 
- The instruments should be illuminated and the luminance should be adjustable in such a way, that they can be read both in daytime and during darkness. They must be designed and located in a manner which avoids annoying reflections in the windows.

- Panels should be made of a matt, dark material, also preventing reflections.

- Earthmoving machines which are being driven or worked on banks and slopes, should be fitted with an acoustic alarm, which gives warning when the safe angle of inclination is exceeded.

- Provision must be made to checkthe correct operation of signal lights and acoustic alarms. 


\section{Lighting}

Efficient lighting on the machine, illuminating the site both in front and to the rear of the machine, must be provided. In addition, effective lighting of the cabin and instruments is essential. Irrespective of lighting required for driving on public roads, the following site illumination aspects are important.

\subsection{Site illumination}

Wheel-loaders, bulldozers, graders, front of back-hoe loaders

- At the front a site lighting system should be mounted which can illuminate at least the extreme ends of the bucket or blade in high, low or lateral positions (broad beam), as well as the direction of travel (long range).

- In articulated wheelloaders lights must be fitted so that the light beams turn with the front section of the machine.

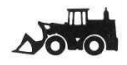

- For reversing, the direction of rearward travel should be lighted by long range lamps. Such lights should be switched on and off automatically when the direction of travel is reversed, so that personnel on the site are not blinded unneccessarily.

- In articulated wheel-loaders the lighting to the rear should be fitted in a manner permitting the light beams to turn with the rear section of the machine.

\section{$\Delta 0 \cdot 0$}

Hydraulic excavators, draglines and rear of back-hoe loaders

- On the cabinm the lift boom and the digging boom, lights must be fitted which illuminate the digging boom and bucket in both high and low positions. In general broad beam lamps may be used - in the case of draglines at the top of the jib. 


\section{General}

- Site lighting should be such that parts of the lift mechanism or of the chassis do not project into the light beams.

- The illumination of the location of the bucket should be efficient. 


\subsection{Other lighting}

- The cabin should incorporate non-glare interior lighting, providing ulluminance of approximately 100 lux. Reflecting surfaces within the cabin should be avoided.

- The instrument- and control panels should have localized illumination, with adjustable luminance. A battery lamp of adequate capacity should be permanently located in the cabin.

- The cabin should also have a socket for an inspection lamp (for repairs etc.).

- For save entering and leaving the acces routes shall be provided with illumination. 


\section{Noise}

- Over the years an operator may be subjected to noise for 8 hours per day or more. The safe equivalent noise level is $L e q=80 \mathrm{~dB}(\mathrm{~A})$. Account should be taken of noise levels within cabins while driving, or performing earthmoving activities. Lower levels are advisable, in order to facilitate communications between the operator and others on the site.

- When attempting soundproofing, one should aim at noise reduction as near as possible to the source (lownoise engines, the greatest possible distance between engine and cabin, engine compartment lined with soundproofing material). The engine compartment should be designed with a view to simple and adequate removal and installation.

- Dominating "pure tones" should be avoided.

- By preference the cabins of articulated wheelloaders should be mounted on the front section, thereby reducing noise transmission from the engine.

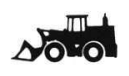




\section{Vibration and shocks}

\section{Engine vibration}

- If there is a possibility that engine vibrations penetrate into the cabin, the latter should be mounted on good quality vibration dampers.

\section{Vibration or shocks as a consequence of the operation of moving equipment}

- The hydraulic cylinders for the operation of the digging boom or bucket should have shockabsorbing stops.

- The construction of the moving equipment must not permit extended movement of bucket or boom, in the event of small movements of the operating controls.

- It is recommended that back-hoe loadersand wheeled hydraulic excavators have jacks or a stabilizer, to absorb shocks and vibration, resulting the suspension of the machine or of its tyres, during excavating activities.

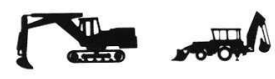

\section{Vibration or shocks as a consequence of driving}

Severe vertical or horizontal vibrations may occur while driving in rough terrain or on roads under construction. In connection with human sensitivity to lengthy exposure to vibration and shocks in the low frequency range of $1-20 \mathrm{~Hz}$, it is most important that vibration and shocks are damped out as much as possible, and as close as possible to the source. When feasible a system of suspension and damping between the axles and the chassis, which can be locked while operating the moving equipment should be fitted. If vibrations cannot be damped close to the source, damping of the cabin or of the seating system should be provided.* It can be seen from existing literature, that most seats on the market at present, are not satisfactory, as these may resonate. The following recommendations for the damping of vertical vibrations apply to the damping of the seating system:

* "Seating system" is understood to mean the seat, occupied by a

person, taking into account the distribution of body weight.

- The vibration frequency of the "seating system" in a vertical plane shall be not more than half of the lowest dominant vibration frequency of the earth-moving machine while working under the most severe conditions. In terms of operation of a wheeled earthmoving 
machine such conditions generally result in a greater than usual spring travel. This should not be greater than $75 \mathrm{~mm}$ above and below the rest position of the occupied seat (see also chapter 4 Seating accommodation and chapter 6 Operating controls).

- In order to absorb sudden or severe vibration and shocks a progressive damping force should be applied. If a passive damping system cannot achieve this, an active damping system (with servo-operation) should be used.

- The seat should have adequate damping in the extreme position, preventing severe shock forces in the event of possible bottoming.

- The "dry friction" of the spring-damping mechanism of the seat should be kept at a minimum.

- Preferably an automatically controlled weight adjustment of the seating system should be incorporated, on the basis of the experience, that one is inclined to set the suspension too "hard".

- The spring damping mechanism of the seat should on no account be such, that vertical damping is converted into a rebound in a horizontal direction.

- The adjustment mechanism of the seat and of its cabin floor attachments should be such, that the seat does not show any play in the adjusted position, preventing unnecessary shocks.

- The spring damping mechanism must remain resistant during a period of several years, against the often rough conditions, and simple replacement must be possible.

- Seating systems must also satisfy as a minimum the requirements of the provisional standard ISO/DIS 7096. The Kz-value used in this standard, should however be less than, or equal to 12. 


\section{Climate and ventilation}

Climatic and ventilation aspects of the cabin deserve the necessary attention. As a consequence of the necessarily large window areas, during summer too much heat may be generated, and during winter too much loss of heat may occur. Hence an airconditioning system for the cabin should be considered. For earthmoving machines which are frequently used in rough conditions, whereby in dry periods dust may enter the cabin, such a system, incorporating an air filter, is essential. The following requirements must be met.

- A fan heater should be fitted in the cabin in a fixed location. During mild frost (to $-5^{\circ} \mathrm{C}$ ) an average temperature of $18^{\circ}$ should be achieved in the cabin. In that case the difference between the airtemperature at floor level and that at ceiling level should not exceed $5^{\circ} \mathrm{C}$.

- The fan heater should draw in cold outside air and discharge warm air. Air velocities within the cabin should not exceed $0.25 \mathrm{~m} / \mathrm{s}$. Combustion gases must not be permitted to enter the cabin.

- The heater should have adequate capacity to keep windows free of condensation and, in the case of frost, free of ice.

- In unglassed areas, wall panels, ceiling and floor must be provided with heat insulation coverings.

- Special attention should be paid to draught-free closures and to the necessity of keeping doors, windows, hatches and trunking of control rods, circuits or cables in the floor and walls of the cabin, closed during long periods. If there is no airconditioning system, the cabin should have at least two opening windows permitting a cross flow of air. It must be possible to lock these windows in various positions, by means of a locking device.

- The cabin should have a provision to direct a cool airflow, at controllable velocity, at the operator's head.

- In dusty conditions a pressurized cabin should be used. 
List of standards of the International Organisation for Standardization (ISO), to which reference is made in the text.

ISO 2631 Guide for the evaluation of human exposure to wholebody vibration, 1978

ISO 2867 Earth-moving machinery-Access systems, 1976

ISO/DP 3411 Earth-moving machinery-Human PhysicalDimensions of ISO 3411 Operators and Minimum Operator Space Envelope, 1979

ISO 3449 Earth-moving machinery-Falling object protective structures - Laboratory tests and performance requirements, 1979 (FOPS)

ISO 3471 Earth-moving machinery-Roll over protective structuresLaboratory tests and performance requirements, 1975 (ROPS)

ISO 6011 Earth-moving machinery - Operating instrumentation, 1978

ISO/DIS 6405 Earth-moving machinery - Symbols - Operator controls and others, 1980

ISO 6682 Earth-moving machinery-Zones of comfort and reach for controls, 1980

ISO/DIS 6683 Earth-moving machinery - Seat belt and seat belt anchorages, 1980

ISO/DIS 7096 Earth-moving machinery - Operator seat - measurement of transmitted vibration, 1980

List of standards of the Nederlands Normalisatie Instituut, to which reference is made in the text

NEN 2027 Mobile cranes: constructional requirements relating to safety, 1982

NEN 2028 Hoisting cranes: automatic limiting devices, 1982 

A joint publication by:

Bedrijfsgezondheidsdienst voor de Bouw-

BG nijverheid

BOUw (Foundation Occupational Health in the Building and Construction Industry)

(P.O. Box 8114, 1005 AC Amsterdam)

ILD Nederlands Instituut voor Praeventieve Gezondheidszorg-TNO, Leiden.

(Netherlands Institute for Preventive Health Care - TNO) 